\title{
Society for Healthcare Epidemiology (SHEA) Mourns the Passing of Past Presidents
}

With great sadness, we note the loss of 2 prominent healthcare epidemiologists in 2017: Drs. Walter J. Hierholzer, Jr., and Barry M. Farr. Both men were prominent advocates for SHEA who mentored many other influential epidemiologists who carry on their legacies. Several members reached out to include their own thoughts about their mentors; excerpts and highlights are provided below. For their full remarks, please visit the SHEA website.

\section{Walter J. Hierholzer, Jr., MD (1935-2017)}

Jan Patterson, MD, FSHEA; Louise Marie Dembry, MD, MS, MBA, FSHEA

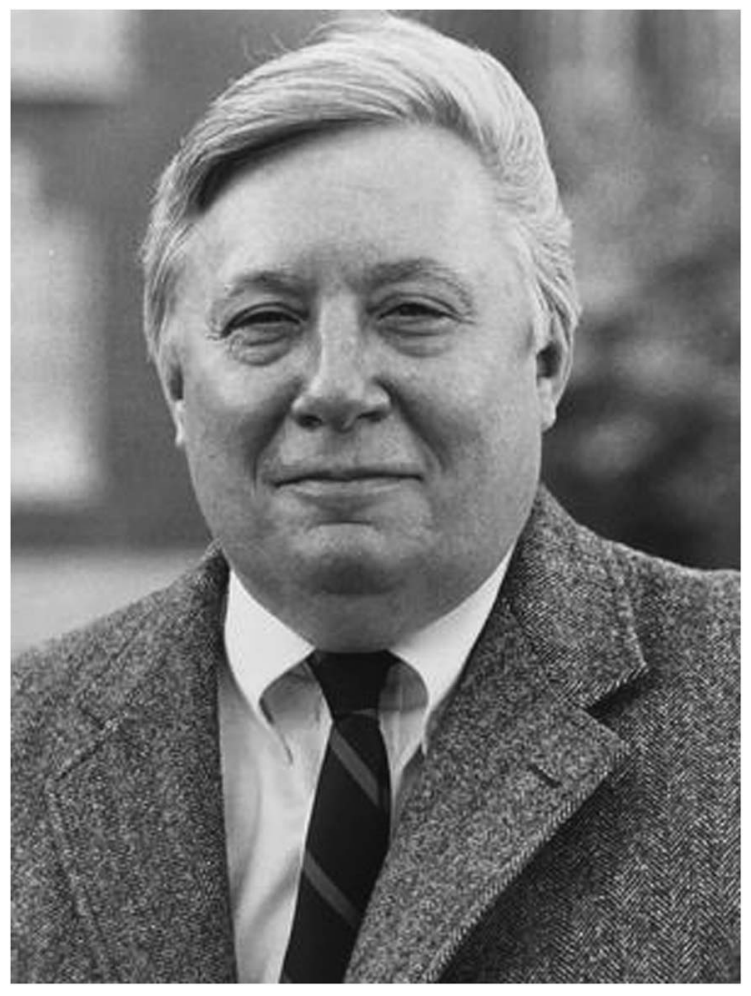

Walter J. Hierholzer, Jr. (1935-2017)

Dr. Walter J. Hierholzer, Jr., was an early adopter and aficionado of bioinformatics as applied to healthcare epidemiology. He was a strong proponent of developing data systems to better understand the risks leading to hospital-acquired infections and other adverse events. He presented a memorable lecture "Health Care Data, The
Epidemiologist's Sand: Comments on the Quantity and Quality of Data" at the 1990 Centers for Disease Control and Prevention Decennial Conference on Nosocomial Infections. In it, Walter used the analogy of the quality of sand required for the production of lens instruments to gain perspective on the increasing amount 
of data available. He wrote that we must begin with quality data if we are to construct a beautiful instrument to use for healthcare improvements. His comments, made almost 3 decades ago, were prescient and are as relevant today as ever.

Walter was an original member of SHEA and served as the President of SHEA's Board of Trustees in 1989 and as a Chair of the Healthcare Infection Control Prevention Advisory Committee from 1992 to 1998. In 2000, he was awarded the SHEA Lectureship for his dedication to the Society and his influence on the field. A master of epidemiology, he modeled and taught the practical aspects of being a successful healthcare epidemiologist to his mentees. He negotiated with the hospital for an associate hospital epidemiologist model so that a junior person could gain extensive experience under his tutelage. $\mathrm{He}$ taught by model and advice; one of his key teachings was to schedule regular and frequent meetings with the hospital administrators. He would comment "They can always cancel, but you are on their calendar and they can't cancel every time." He won the trust of hospital administrators with his expertise and frequent advice. He was a fearless yet humble leader. We recognize his contributions to the field and are saddened by his loss.

\title{
Barry M. Farr, MD, MSc (1951-2017)
}

\author{
John Jernigan, MD, MS; Cassandra Salgado, MD, MS; David Calfee, MD, MS; \\ Robert Sherertz, MD; Karin Byers, MD; \\ Leonard A. Mermel, DO, ScM, AM (Hon), FSHEA, FIDSA, FACP
}

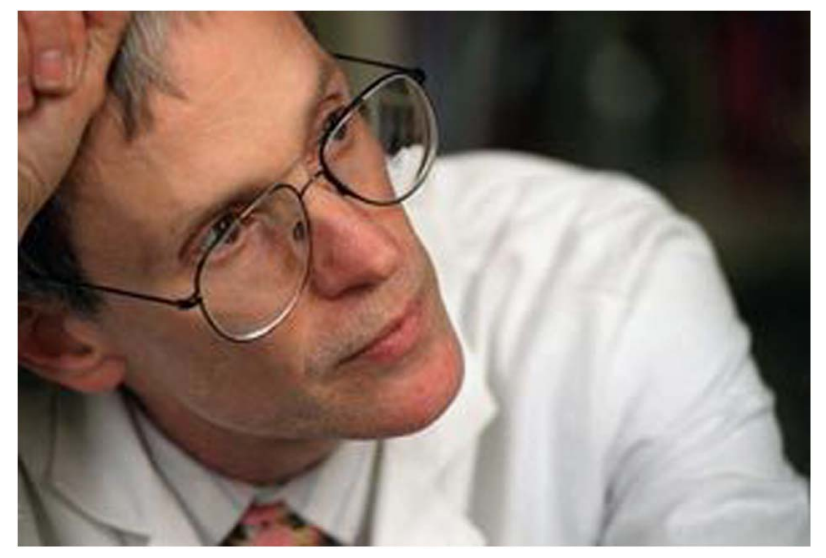

Barry M. Farr (1951-2017)

Dr. Barry Farr was our mentor and colleague as well as our friend. Barry's musings were a delightfully interesting mixture of epidemiology, literature, and philosophy, with a healthy dose of laughter interjected throughout. Frequently, as these conversations ended, he would open his desk drawer and pull out a yellowed piece of paper, which I think he'd kept since he was an ID fellow, from which he would read the words of the physicist Michael Faraday, "Work, finish, publish."

Barry's legacy of the thoughtful pursuit of evidence-based measures to keep hospital patients safe will be firmly cemented within the field of infection prevention and hospital epidemiology. Barry was generous with his time, knowledge, experience, and advice. He held us and himself to high standards and lived by example. He introduced his mentees to leaders in the field, encouraged us to get involved in SHEA, and helped identify opportunities for us to grow as researchers, epidemiologists, and patient safety advocates. Barry set a very high bar.
For those of you who never knew Barry, you should read his book about multiple sclerosis (MS). Every paragraph explodes with the passion and courage with which he faced life and his MS. Barry had always wanted to write the great American novel; he finished a first draft before he died and his three sons, all college English majors, will finish it.

Dr. Barry Farr stood up to the strongest foes if he believed in his heart that his position was the best practice based on the available evidence and in the best interest of the patients we serve. Barry was one of the bravest individuals we have met and certainly one of the most brilliant. He was loved by anyone who had the chance to know him. His passing is a great loss for the "people of Barry" and the world of infectious diseases. He will be sorely missed. 